San Jose State University

SJSU ScholarWorks

Master's Theses

Master's Theses and Graduate Research

Spring 2020

\title{
Assessing the Relationship Between Narcissism, Neuroticism, and Leadership Skills
}

Krista Marie Brooker

San Jose State University

Follow this and additional works at: https://scholarworks.sjsu.edu/etd_theses

\section{Recommended Citation}

Brooker, Krista Marie, "Assessing the Relationship Between Narcissism, Neuroticism, and Leadership Skills" (2020). Master's Theses. 5087.

DOI: https://doi.org/10.31979/etd.tbfj-g3q6

https://scholarworks.sjsu.edu/etd_theses/5087

This Thesis is brought to you for free and open access by the Master's Theses and Graduate Research at SJSU ScholarWorks. It has been accepted for inclusion in Master's Theses by an authorized administrator of SJSU ScholarWorks. For more information, please contact scholarworks@sjsu.edu. 


\title{
ASSESSING THE RELATIONSHIP BETWEEN NARCISSISM, NEUROTICISM, AND LEADERSHIP SKILLS
}

\author{
A Thesis \\ Presented to \\ The Faculty of the Department of Psychology \\ San José State University \\ In Partial Fulfillment \\ of the Requirements for the Degree \\ Master of Science
}

by

Krista M. Brooker

May 2020 
(C) 2020

Krista M. Brooker

ALL RIGHTS RESERVED 
The Designated Thesis Committee Approves the Thesis Titled

ASSESSING THE RELATIONSHIP BETWEEN NARCISSISM, NEUROTICISM, AND LEADERSHIP SKILLS

by

Krista M. Brooker

APPROVED FOR THE DEPARTMENT OF PSYCHOLOGY

SAN JOSÉ STATE UNIVERSITY

May 2020

Dr. Howard Tokunaga

Dr. Megumi Hosoda

Kelly Harcourt-Wood
Department of Psychology

Department of Psychology

Equinix Inc. 


\section{ABSTRACT \\ ASSESSING THE RELATIONSHIP BETWEEN NARCISSISM, NEUROTICISM, AND LEADERSHIP SKILLS}

\section{by Krista M. Brooker}

Understanding personality traits that are related to leadership skills is important in order to hire effective leaders. Research has seldom examined the relationship between narcissism, neuroticism, and leadership skills. Therefore, the present study was conducted to examine the relationship between narcissism, neuroticism, and leadership skills (human skills and conceptual skills). It was hypothesized that narcissism would be positively related to human skills and conceptual skills. It was also hypothesized that neuroticism would be negatively related to human skills and conceptual skills. A total of 145 employees participated in the self-report survey. Results showed that there was no relationship between narcissism and leadership skills. Results also indicated that neuroticism was negatively related to human skills and conceptual skills. Results implied the more neurotic employees were, the fewer leadership skills they had. When subsamples were created for age, there was no relationship between neuroticism and leadership skills for respondents younger than 25 years old, but the relationship was negative for employees 25 years or older. Based on these findings, there is a need for research examining additional demographic variables and the relationship between neuroticism and leadership skills. 


\section{ACKNOWLEDGMENTS}

I would like to take the time to thank everyone who has been there by my side during the thesis process. None of this could have been possible without the countless hours my professors have spent guiding me towards the final piece. Howard, thank you for being so committed, patient, and supportive. Megumi, thank you for always being so optimistic, insightful, and dedicated. I am beyond grateful to have had such amazing professors during my time at SJSU and I will never forget this experience.

I would also like to thank my Mom and Dad (Sheila and Mark Brooker). Thank you for always being there for me ever since I was little. You have supported me throughout my whole life and believed in me. Your love and confidence helped me achieve great things, and I am incredibly grateful for that. I love you guys!

Lastly, this goes to all my friends and loved ones who have cheered me on. Thank you for pushing me to do my best and for being the best support system ever. It genuinely felt like a group effort and you all have made the process memorable. From staying in on the weekends studying all night together, to listening to me vent about the times where everything seemed to be failing, you never stopped believing in me. I truly am a lucky girl to have such exceptional people in my life. 


\section{TABLE OF CONTENTS}

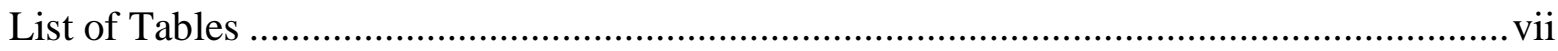

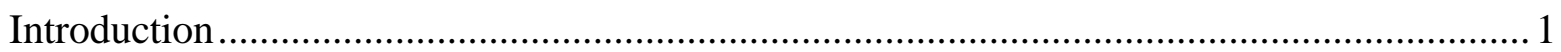

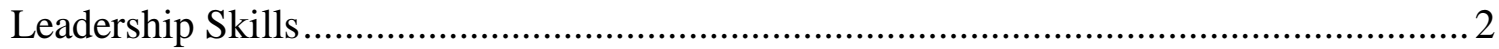

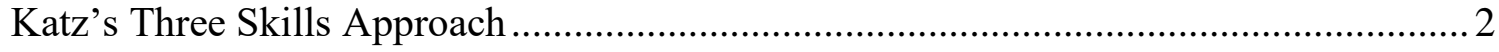

Mumford's Leadership Skills Approach.................................................................

Importance of Leadership Skills ................................................................................

Previously Used Antecedents of Leadership Skills ..................................................... 10

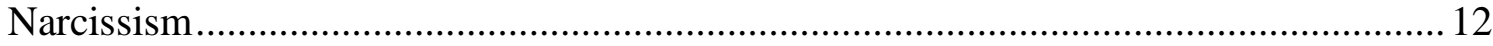

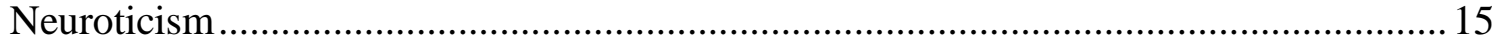

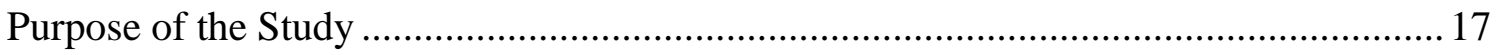

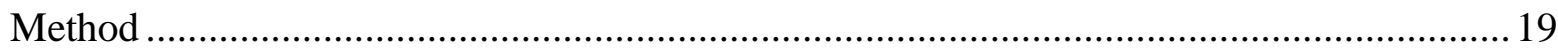

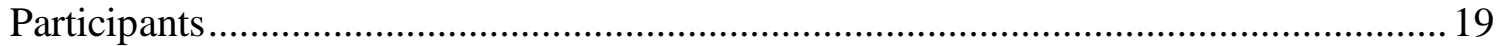

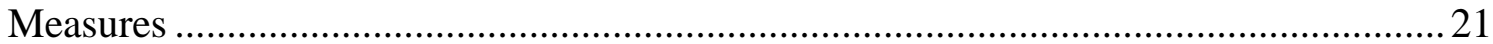

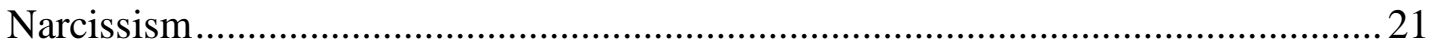

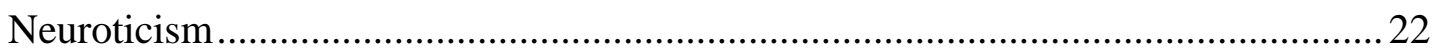

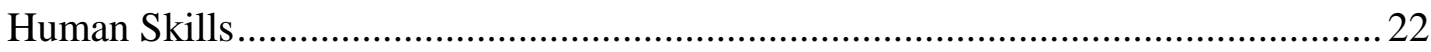

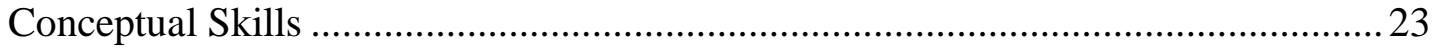

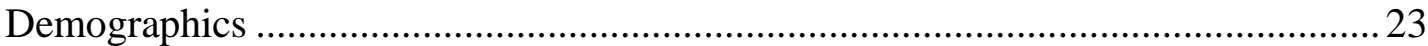

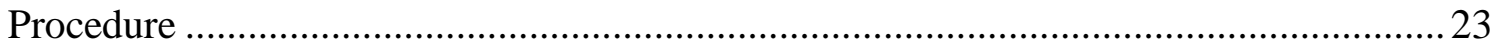

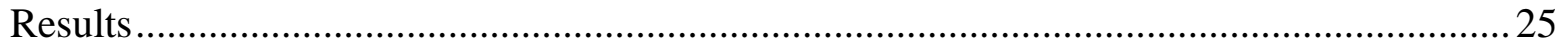

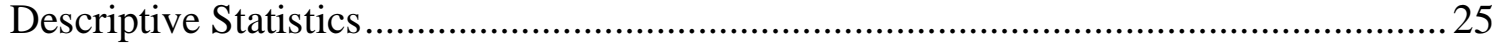

Test of Research Hypotheses ....................................................................................26

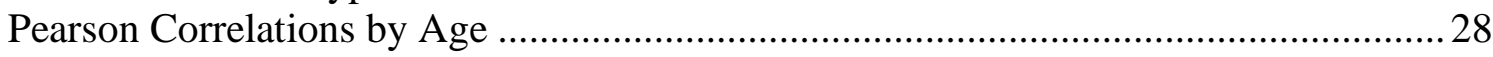

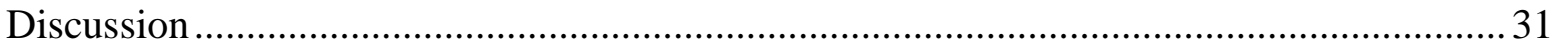

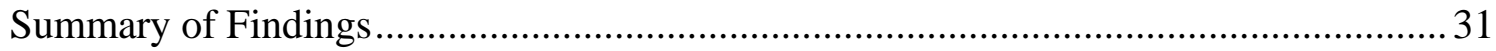

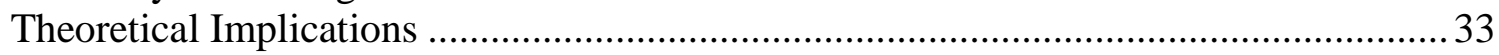

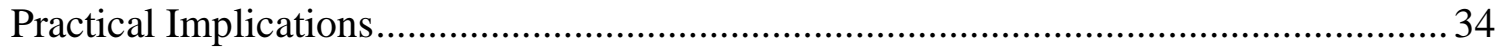

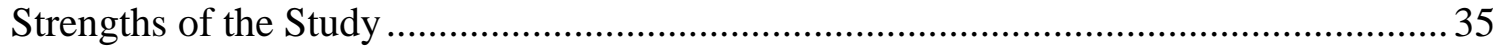

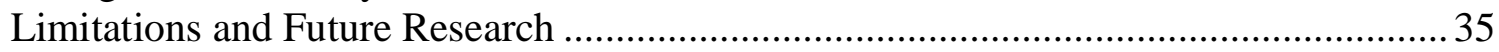

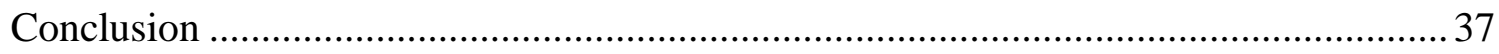

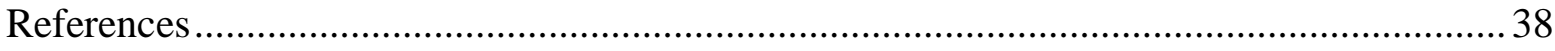

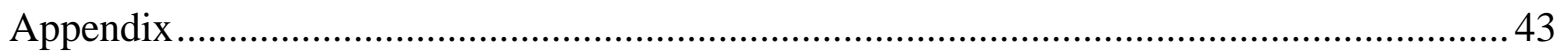

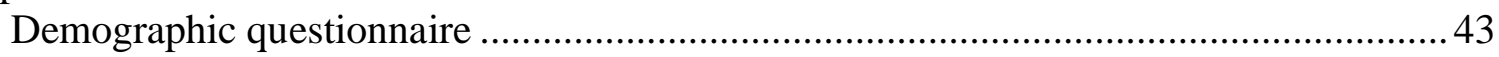

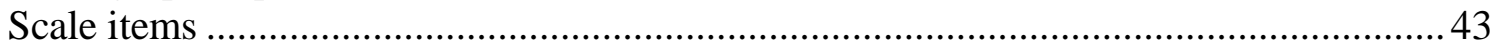




\section{LIST OF TABLES}

Table 1. Demographic and Background Characteristics of Participants ........................20

Table 2. Descriptive Statistics of Variables ............................................................26

Table 3. Pearson Correlations of Predictor and Criterion Variables ...............................27

Table 4. Pearson Correlations, Neuroticism and Criterion Variables

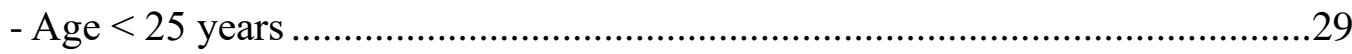

Table 5. Pearson Correlations, Neuroticism and Criterion Variables

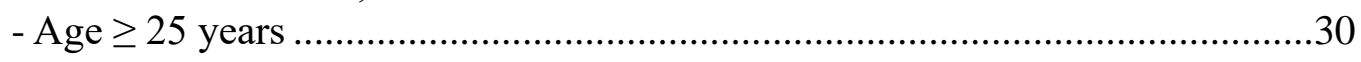




\section{Introduction}

Leadership is a critical element of any business and has a profound impact on a company's consequences such as employee productivity and reaching business goals (McFarlin \& Sweeney, 2010). Leadership can be defined as the ability and willingness to take ownership of an organization (or the component of the organization one is charged with managing), combined with a drive to do what is best for the organization (Rihal, 2017). Leaders set and achieve challenging goals, take fast and decisive action when needed, aim to outperform the competition, and inspire others to perform at the highest level they can. For any project to be successful, the choice of a competent leader is crucial. Leaders have a vision to express to the team and this vision is meant to be taken action on. A vision is a conceptualization of a future and better state, which the leader navigates the organization. The effectiveness of a leader is very important and can be measured through a certain skill set.

It is common to look at personality traits to determine if an employee has the skill set to be a leader. However, research that examines the relationship between narcissism and neuroticism and leadership skills is scarce. Given that leaders are an asset to organizations, there is need for research that examines variables that can potentially predict leadership skills. Thus, the primary goal of this study was to clarify the relationship between narcissism and neuroticism and leadership skills (human skills and conceptual skills). 


\section{Leadership Skills}

Simply having the responsibilities of a leader does not necessarily make a person an effective leader. There are many leadership skills and competencies that, when combined and applied, contribute to effective leadership. A skill implies an ability which can be developed, not necessarily inborn, which is manifested in performance, not merely in potential (Katz, 1974). Skills determine what leaders can achieve, whereas traits indicate who they are based on their intrinsic characteristics. Previously, researchers believed that traits predict leadership (e.g., Katz, 1974). Researchers have also studied leadership skills and abilities for a number of years (e.g., Northouse, 2010). There are two main influential models regarding leadership skills, which can be seen as complementary to each other because they offer different views on leadership in terms of skills.

\section{Katz's Three Skills Approach}

The first approach, which will be utilized in this study, is called the three skills approach by Robert L. Katz (Katz, 1955). Katz published an article in the Harvard Business Review in 1955 that explained that leadership was not best predicted by traits but rather by a set of skills. Before his publication, researchers believed that traits predicted leadership, and was the first approach to leadership that is centered around skills. Additionally, this approach is appealing because it makes leadership achievable by anyone because skills can be developed, as opposed to traits, which are not developable and rather innate.

According to Katz, leadership is based on three dimensions of skills: technical, human, and conceptual. This study will focus on the human skills and conceptual skills in 
Katz's model. Technical skills are proficiency, based on specific knowledge, in a particular area of work (Northouse, 2010). Having technical skills means that a person is competent and knowledgeable with respect to the activities specific to an organization, the organization's rules and standard operating procedures, and the organization's products and services (Katz, 1974; Yukl, 2006). Technical skills will not be examined in this study because they become less of a requirement the stronger someone is in the organization, as compared to human and conceptual skills, which become more important the higher someone is in an organization (Katz, 1955). Human skills and conceptual skills will be expanded on to illuminate their importance in leadership.

The first dimension of skills I will focus on are human skills. Human skills, also known as interpersonal skills, include proficiency working with people, knowledge of human behavior and how to communicate effectively (Northouse, 2010). People with strong human skills have the ability to work cooperatively with others, inspire enthusiasm, motivate and build trust (Muthuveloo, Chiek, \& Ping, 2017). Human skills are required to effectively influence superiors, peers, and subordinates in the achievement of organizational goals. These skills enable a leader to influence a team or group members to work together to accomplish organizational goals and objectives (Katz, 1974).

Leaders with highly developed human skills are aware of their own attitudes and their assumptions and beliefs about other individuals and groups. People with strong human skills are able to see the usefulness and limitations of their own feelings. By accepting the existence of viewpoints, perceptions, and beliefs different from their own, leaders with strong human skills are able to understand what others really mean by their words or 
behavior (Katz, 1974). Leaders with strong levels of interpersonal skills are able to adapt their own ideas to other people's ideas, especially when this aids in achieving organizational goals quickly and efficiently (Northouse, 2010). These leaders are sensitive and empathetic to what motivates others, create an atmosphere of trust for their followers, and take others' needs and motivations into account when deciding how to achieve organizational goals. Many studies have found human skills to be a more important predictor of managerial effectiveness than technical skills or conceptual skills (Carmeli \& Tishler, 2006; Teoh, Lee, \& Muthuveloo, 2017).

Leaders need to develop their human skills to be effective leaders. Human skills must become a natural, continuous activity because they involve sensitivity not only at times of decision making but also in day-to-day behaviors. Thus, to be effective, human skills must be naturally developed and unconsciously and consistently demonstrated in the leader's every action. Interpersonal skills are required at all three levels of management: supervisory, middle management, and upper management (Katz, 1974; Yukl, 2006). These skills help leaders to get along with people and to communicate and work within teams.

The second dimension of skills I will focus on are conceptual skills. Conceptual skills are defined as the ability to see an organization as a whole or to have a systematic viewpoint (Northouse, 2012; Yukl, 2002). Conceptual skills include recognizing how the various functions of an organization depend on one another, and how changes in any part affect the others. They extend to visualizing the relationship between the organization and the industry, community, and political, social, and economic forces of the nation as a 
whole (Katz, 1974). Recognizing these relationships, leaders should be able to act in a way that advances the welfare of the organization. Leaders with stronger levels of conceptual skills are good at thinking through ideas that shape an organization and its vision for the future, expressing these ideas in verbal and written form, and understanding and expressing the economic principles underlying their organization's effectiveness.

Conceptual skills are extremely important for top managers, somewhat important for middle managers, and less important for supervisory managers (Northouse, 2010). Although conceptual skills are less important at lower levels of management, it is important to develop and demonstrate these skills in order to be promoted to higher levels of management (Yukl, 2006). These skills enable leaders to understand and better determine the actions and measures to be taken in a particular field of work.

\section{Mumford's Leadership Skills Approach}

The second approach is called the leadership skills approach by Michael Mumford and colleagues (Mumford, Marks, Connelly, Zaccaro, \& Reiter-Palmon, 2000). Mumford and his colleagues identified a new skills-based model of organizational leadership based on Katz' (1955) three skills approach model. Mumford and colleagues attempted to explain effective performance and used a capability model to explain the relationship between a leader's skills and knowledge. This model does not focus on what leaders do, but rather focuses on their capabilities.

Mumford's leadership skills approach has five elements: competencies, individual attributes, leadership outcomes, career experiences, and environmental influences. Competencies are the most important element - the "kingpin" in this model (Northouse, 
2010). It is relevant to only discuss the competencies component for the interests of this study because it is the only element of the model that is based on skills. The other four elements of the model are based on leadership effectiveness. Mumford and colleagues (2000) identified three aspects of competencies that result in effective leadership: problem solving, social judgment, and knowledge. The three aspects work together and separately to affect outcomes.

Problem solving skills are creative abilities leaders bring to unique and vague organizational problems. Problem solving skills include defining important problems and issues, accumulating information related to a problem or issue, developing new ways to comprehend each problem or issue, and developing unique alternatives for solving problems and issues. Problem-solving skills require leaders to be aware of their own capacities and challenges relative to the problem or issue and the organizational context (Mumford et al., 2000).

Social judgment skills enable leaders to comprehend people and the social systems within which they work, play, and have a social life (Mumford et al., 2000). Social judgment skills involve working with others to lead change, solve problems, and make sense of issues. Social judgment includes four elements: perspective taking, social perceptiveness, behavioral flexibility, and social performance. Perspective taking is understanding attitudes others have toward a particular problem or solution. Social perceptiveness is having insight and awareness into how others within the organization function. Behavioral flexibility is the capacity to change and adapt one's behavior due to 
others' perspectives in the organization. Social performance is the capacity to effectively communicate one's vision to others based on an understanding of others' perspectives.

Knowledge, the third aspect of competencies, is the accumulation of information and the mental structures (schema) used to organize the information. Knowledgeable leaders have strongly developed and complex schemata that are used to collect and organize data. More knowledgeable leaders are able to consider complex organizational issues and develop alternative and appropriate strategies for change. Knowledge allows leaders to use prior experiences to constructively plan for and change the future. Knowledge and expertise make it possible for people to think about complex systems issues and identify strategies for change (Northouse, 2007).

The leadership skills approach by Mumford and colleagues (2000) will not be used in this study because the model suggests that leadership effectiveness, which is measured by outcomes, is a direct result of leader competencies. I do not want to look at outcomes, rather, the current study wants to be able to predict if one has a set of leadership skills, more specifically, human skills and conceptual skills. I want to see if one has the potential to obtain a set of skills, rather than looking at their current results or outcomes. Therefore, Katz' (1955) three skills approach is better molded for the interests of this study.

\section{Importance of Leadership Skills}

It is important, as a leader, to develop human skills and conceptual skills because they dramatically affect an organization at different levels. More specifically, research has looked at the relationship between leadership skills and leader effectiveness and 
organizational efficiency. Leaders want to be effective and want their organization to be efficient, therefore, this can be achieved by leaders having human skills and conceptual skills. First, I will discuss why managerial effectiveness is important and how human skills and conceptual skills are linked to managerial effectiveness.

Managerial effectiveness is defined as a manager's ability to achieve desired results by applying his/her skills and abilities (Mahajan \& Chaturvedi, 2013). Managerial effectiveness has been found to be an important factor for an organization to stay competitive (Sanyal \& Guvenli, 2004). Yet, the attributes and characteristics that exemplify a managerial career are shifting (Mutuveloo et al., 2017). The competencies required to be an effective manager in the past may not be adequate in the emerging organizational forms of the 21 st century. Because of this, it becomes crucial to find out what attributes or skills are important for managers to be effective both locally and internationally.

Muthuveloo and colleagues (2017), who utilized Katz' three skills approach model, conducted a research study to examine the relationships between five managerial skills (technical skill, human skill, conceptual skill, emotional intelligence skill, and communication skill) and managerial effectiveness. Emotional intelligence is defined as the ability to perceive, express, understand, use and manage emotions accurately and adaptively (Salovey \& Pizarro, 2003). According to the survey results, they found that human skills were positively related to managerial effectiveness. Because of the fact that managers get things done through others, human skills were perceived to be an essential skill in influencing managerial effectiveness. In a research study by El-Sabaa (2001) 
among project managers from private and public sector organizations, human skills were also rated as the most important management skill.

The results from Muthuveloo and colleague's (2017) study also found that conceptual skills were positively related to managerial effectiveness. The structural model results indicated that conceptual skills had the strongest relationship, compared to the other four managerial skills (technical, human, emotional intelligence, communication), with managerial effectiveness. These results were consistent with a previous study by Tonidandel, Braddy, and Fleenor (2012), who found that conceptual skills were a significant predictor of managerial or leadership effectiveness. In many other literatures, conceptual skills, which require complex and integrative thinking, have been closely associated with competencies required by high level leaders (Northouse, 2012).

Next, I will discuss why organizational efficiency is important and how human skills and conceptual skills are linked to organizational efficiency. In order to assess managers' performance and determine their success and effectiveness, we can use efficiency as a measure. Performance efficiency is a measure that assesses the cost of resources used in the process of gaining goals by comparing the outputs obtained to input consumed. Efficiency is important for profitability by saving both time and money, thus making businesses more profitable. Javadin, Tehrani, and Ramezani (2010), who utilized Katz' three skills approach model, conducted a research study. According to the survey results, they found a positive relationship between both human skills and conceptual skills and branch efficiency. In conclusion, an increase in efficiency depended on the use of effective human skills and conceptual skills in branches. 


\section{Previously Used Antecedents of Leadership Skills}

It is important to be knowledgeable of factors that are related to human skills and conceptual skills. It is easier to hire an effective and efficient leader by being aware of variables that are related to these skills. Although there is growing consensus regarding the outcomes of human and conceptual skills, there is less agreement on their antecedents (Rubin, Bommer, \& Baldwin, 2002). Demographic variables, participation in extracurricular activities, and personality traits have been studied as predictors of human skills and conceptual skills.

The modern workplace is diverse, filled with men and women from every culture. Kaifi and Mujtaba (2010) aimed to see if gender was a valid predictor of human and conceptual skills. Kaifi and Mujtaba utilized Katz' (1955) three skills approach model to define human skills and conceptual skills and the skills inventory by Northouse (2010) to measure these skills. Kaifi and Mujtaba (2010) distributed Northouse's (2010) survey and it was completed by 200 participants who worked for different organizations. In this study, men had higher scores on human skills than women, who had significantly higher scores on conceptual skills than men.

Aside from gender predicting human skills and conceptual skills, participation in extracurricular activities also predicts these skills. Extracurricular activities include, but are not limited to, sports teams, clubs, and fraternities/sororities. One intuitive notion is that extracurricular activities are a place where people look to utilize, and perhaps refine and develop, their interpersonal skills. Rubin and colleagues (2002) found participation in extracurricular activities was positively related to interpersonal skills. More specifically, 
people who were members of extracurricular groups exhibited superior interpersonal skills. Rubin and colleagues (2002) concluded that extracurricular involvement was associated with stronger communication, initiative, decision-making, and teamwork skills.

In addition to gender and extracurricular activities, personality traits also predict human skills and conceptual skills. Personality traits differentiate individuals based on their tendencies to think, feel, and behave (Ones, Viswesvaran, \& Dilchert, 2005) and therefore can help to elucidate why a leader may be more or less successful. Personality traits are popular predictors in many studies, but more specifically in predicting interpersonal skills. The five-factor model, also known as the Big Five personality traits, is a taxonomy for personality traits (Costa \& McCrae, 1980). The Five Factor Model includes openness to experience, conscientiousness, extraversion, agreeableness, and neuroticism. One of the traits, extraversion, is defined as the tendency to participate in and enjoy social interactions (Ashton \& Lee, 2007). Extraversion indicates how outgoing and social a person is. According to previous research, those who reported higher levels of extraversion also indicated greater interpersonal competency (Jenkins-Guarnieri, Wright, \& Johnson, 2013). This research parallels earlier research by Ozer and BenetMartinez (2006), who found extraversion to be positively associated with interpersonal competency.

Although previous research has looked at personality traits as a predictor to human and conceptual skills, this study precisely wants to look at narcissism and neuroticism as predictors. The next sections will define narcissism and neuroticism and discuss previous research on their relationships with human skills and conceptual skills. 


\section{Narcissism}

Narcissism is defined as a grandiose sense of self-worth, feelings of entitlement, need for admiration, and preoccupation with fantasies of unlimited brilliance, power, or success (Bressert, 2019). Some traits of a narcissist include charm, self-assurance, popularity, selfishness, dominance, and hostility. It should be noted that many narcissist characteristics are "leader-like," such as being socially dominant, extraverted, and having high self-esteem (Ensari, Riggio, Christian, \& Carslaw, 2011; Judge, Heller, \& Mount, 2002). Consistent with these characteristics, narcissism has been associated with social skills and charisma (Back, Schmukle, \& Egloff, 2010; Brunell, Gentry, Capmbell, Hoffman, Kuhnert, \& Demarree, 2008; Nevicka, De Hoogh, Van Vianen, Beersma, \& Mcllwain, 2011a; Nevicka, Ten Velden, De Hoogh, \& Van Vianen, 2011b; Paulhus, 1998).

Narcissism has been associated with work-related variables other than the human skills and conceptual skills this study is interested in. Kanten (2014) conducted a selfreport study to investigate the effect of narcissistic personality characteristics on organizational citizenship behaviors. Organizational citizenship behaviors are behaviors that exceed delineated role expectations but are important and even crucial for an organization's survival (Brief \& Motowildo, 1986; Katz \& Kahn, 1966). Examples of organizational citizenship behaviors are being punctual, helping others, making suggestions to improve things, and not wasting time at work (Schnake, 1991). In this study, narcissistic personality had a significant, positive relationship with employees' organizational citizenship behaviors, suggesting that the more individuals are 
characterized by a grandiose sense of self-worth, feelings of entitlement, need for admiration, brilliance, success, and power, the more they are to exceed delineated role expectations.

Similar to Kanten's findings, Grijalva, Harms, Newman, Gaddis, and Fraley (2015) conducted a self-report study to investigate the relationship between narcissism and counterproductive work behaviors. Counterproductive work behaviors refer to voluntary behaviors that violate significant organizational norms and threaten the well-being of the organization or its members (Grijalva et al., 2015). Examples of counterproductive work behaviors are making threats, work avoidance, work sabotage and over acts (Spector, 1997). According to Grijalva and colleagues (2015), narcissism was the dominant predictor (compared to Machiavellianism and psychopathy) of counterproductive work behavior, which had a significant, positive relationship. Machiavellianism is defined as a personality trait that is characterized by manipulative and exploitative attitude toward others, lack of empathy, and a cynical view of human nature (Tamas, Andras, \& Tamas, 2016). Psychopathy is defined as a disorder marked by deficient emotional responses, lack of empathy, and poor behavioral controls, commonly resulting in persistent antisocial deviance and criminal behavior (Anderson \& Kiehl, 2014). The more individuals are characterized by a grandiose sense of self-worth, feelings of entitlement, need for admiration, brilliance, success, and power, the more they are to engage in counterproductive work behaviors.

Judge, LePine, and Rich (2006) conducted a self-report study examining the extent to which narcissism was related to self-ratings of leadership, workplace deviance, and task 
and contextual performance. Workplace deviance is also referred to as "on-the-job-crime" and could be in the form of shirking at work, stealing from the workplace, sabotaging, and harassing other workers (Bagchi \& Bandyopadhyay, 2016). Contextual performance is job performance that supports the broader, organizational, social, and psychological environment in which the technical core must function (Borman \& Motowidlo, 2000).

The results of the study found that narcissism had a significant, positive relationship with enhanced self-ratings of leadership. The more individuals had a grandiose sense of self-worth, feelings of entitlement, and needs for admiration, brilliance, success, and power, the more favorably they rated themselves in regard to their leadership. Narcissism also had a significant, positive relationship with workplace deviance and contextual performance.

These findings indicate that narcissism is related to one's perception of one's leadership ability and performance. The question is whether narcissistic leaders have the desired human skills and conceptual skills. Research on the relationship between narcissism and human skills is limited, but the relationship appears to be negative. For example, Cheek, Kealy, Joyce, and Ogrodniczuk (2018) conducted a study to examine the relationship between narcissism and interpersonal skills. In this study, results indicated that narcissism had a significant, positive relationship with interpersonal impairment, particularly characterized by domineering, vindictive, and overly nurturing behavior (Cheek et al., 2018).

Research on the relationship between narcissism and conceptual skills is also limited and the relationship appears to be uncertain. Blair, Hoffman, and Helland (2008) 
conducted a self-report study to see the relationship between narcissism and conceptual skills. According to Blair and colleagues, narcissism was not significantly related to conceptual skills. These results are inconsistent with theoretical assertions (Kets de Vries \& Miller, 1985), but most assumptions are based on theoretical assertions instead of research studies.

\section{Neuroticism}

The current study also wants to examine the extent to which neuroticism is related to human skills and conceptual skills. Neuroticism is one of the Big Five Factors in the study of personality in psychology (Costa \& McCrae, 1980). The personality trait of neuroticism refers to the relatively stable tendency to respond to threat, frustration, and loss with negative emotions (Lahey, 2009). A neurotic personality is characterized by persistent and often disproportionate worry and anxiety. People with low levels of neuroticism find it easier to remain calm and are less affected by stressful events. The neurotic leader is often cautious and does precise work that is fueled by the fear of disappointing the group. Neurotic leaders are more willing to go to greater lengths to succeed and be effective. "Neurotics are motivated by their anxiety and feelings of inadequacy to work hard" (Adams, 2013, p. 2).

Neuroticism has been associated with work-related variables aside from the human skills and conceptual skills this study is interested in. Vlasveld, van der Feltz-Cornelis, Anema, van Mechelen, Beekman, van Marwijk, and Penninx, (2012) conducted a study to examine the role of personality characteristics in absenteeism. According to the results, workers high in neuroticism had significantly higher short-term absenteeism (0-2 weeks) 
and long-term absenteeism (> 2 weeks). Absenteeism is inevitable, but workplaces do not want workers participating in long-term absenteeism, because it incurs huge financial costs (Vlasveld et al., 2012).

Neuroticism has also been associated with job performance. Tuteja and Sharma (2017) conducted a self-report study to look at the relationship among the Big Five personality traits and job performance. Job performance can be defined as "all the behaviors employees engaged at work" (Jex, 2002, p. 88). Consistent with previous studies, the effects of all five traits on job performance were significant, with neuroticism being the least influential factor compared to agreeableness, conscientiousness, extraversion, and openness to experience.

Research on the relationship between neuroticism and human skills appears to be negative. Feitosa (2013) conducted a self-report study to explore the relationship between neuroticism and social skills. In this study, results indicated that neuroticism had a significant, negative relationship with social skills. Social skills of "conversation" and "social fluency" had stronger correlations with neuroticism. The more individuals were characterized by persistent and often disproportionate worry and anxiety, the less they had social skills, especially when it came to conversation with someone and proficiency in social situations/interpersonal relations.

Research has not yet looked at the relationship between neuroticism and conceptual skills. I want to determine the relationship between neuroticism and conceptual skills because it can be a great predictor of whether people high or low in neuroticism obtain conceptual skills. According to Northouse (2016), as society becomes more advanced and 
aware of personal development as an area of study, the Big Five are going to be more easily incorporated into the skills approach. They will no longer be separate within the traits approach. Researching the relationship between neuroticism and conceptual skills can help integrate the skills approach and traits approach.

\section{Purpose of The Study}

The purpose of the present study is to clarify the relationship between narcissism and neuroticism and leadership skills (human skills and conceptual skills). Given the limited research on the relationship between narcissism and leadership skills, there is little that is currently known regarding the topic of interest. Because narcissism has been found to be associated with interpersonal impairment (Cheek et al., 2018), it seems narcissism is negatively related to human skills. Secondly, the relationship between narcissism and conceptual skills is not known. Blair and colleagues (2008) found narcissism was not significantly related to conceptual skills, which is inconsistent with theoretical assertions (Kets de Vries \& Miller, 1985).

Although there is little known about the relationship between neuroticism and leadership skills, it appears that the relationship between neuroticism and human skills is negative. Feitosa (2013) found neuroticism had a significant, negative relationship with social skills such as "conversation" and "social fluency." Secondly, the relationship between neuroticism and conceptual skills has not been looked at.

The gap for the present study pertains to the unclear relationship between the personality traits of narcissism and neuroticism and the leadership skills of human skills and conceptual skills. There is very limited research regarding these topics with no 
clearly determined relationships. The present study wants to address the current gap regarding the predictors (narcissism and neuroticism) and leadership skills (human skills and conceptual skills).

The main goals of the study are to examine the relationship between narcissism and neuroticism to leadership skills. The present study presents two hypotheses that will be addressed. The first research hypothesis, regarding narcissism, is as follows:

Hypothesis 1a: Narcissism is negatively related to human skills.

Hypothesis $1 b$ : Narcissism is negatively related to conceptual skills.

The second research hypothesis, regarding neuroticism, is as follows:

Hypothesis 2a: Neuroticism is negatively related to human skills.

Hypothesis $2 b$ : Neuroticism is negatively related to conceptual skills. 


\section{Method}

\section{Participants}

A total of 164 individuals participated in this study. Participants were recruited during the winter of 2019/2020 using social networking sites (e.g., Facebook, LinkedIn) and college students at San José State University. Because this was a study on workplace behaviors, participants were required to be employed (full-time or part-time) or retired at the time of data collection. Those who indicated that they were not currently employed were automatically taken to the end of the survey and excluded from data collection. Therefore, the final sample consisted of 145 participants. Table 1 reports demographic information of the sample. 
Table 1

Demographic and Background Characteristics of Participants

\begin{tabular}{|c|c|c|}
\hline Variable & $n$ & $\%$ \\
\hline \multicolumn{3}{|l|}{ Gender } \\
\hline Male & 58 & $40.0 \%$ \\
\hline Female & 86 & $59.3 \%$ \\
\hline Non-binary & 1 & $.7 \%$ \\
\hline \multicolumn{3}{|l|}{ Age } \\
\hline 18-24 years old & 76 & $52.4 \%$ \\
\hline 25-34 years old & 45 & $31.0 \%$ \\
\hline $35-44$ years old & 10 & $6.9 \%$ \\
\hline 45-54 years old & 5 & $3.4 \%$ \\
\hline 55-64 years old & 7 & $4.8 \%$ \\
\hline Over 64 years old & 1 & $1.4 \%$ \\
\hline \multicolumn{3}{|l|}{ Education } \\
\hline High School & 20 & $13.8 \%$ \\
\hline Some college & 40 & $27.6 \%$ \\
\hline Associate's degree & 6 & $4.1 \%$ \\
\hline Bachelor's degree & 49 & $33.8 \%$ \\
\hline Master's degree & 22 & $15.2 \%$ \\
\hline Doctoral or Professional degree & 8 & $5.5 \%$ \\
\hline \multicolumn{3}{|l|}{ Employment Status } \\
\hline Employed Full-Time & 87 & $60.0 \%$ \\
\hline Employed Part-Time & 57 & $39.3 \%$ \\
\hline Retired & 1 & $.7 \%$ \\
\hline \multicolumn{3}{|l|}{ Length of time at current job } \\
\hline Less than 1 year & 51 & $35.2 \%$ \\
\hline $1-3$ years & 65 & $44.8 \%$ \\
\hline 4-6 years & 13 & $9.0 \%$ \\
\hline $7-10$ years & 8 & $5.5 \%$ \\
\hline More than 10 years & 7 & $4.8 \%$ \\
\hline \multicolumn{3}{|l|}{ Hours worked per week } \\
\hline Less than 20 hours & 26 & $17.9 \%$ \\
\hline 21-30 hours & 30 & $20.7 \%$ \\
\hline $31-40$ hours & 47 & $32.4 \%$ \\
\hline More than 40 hours & 41 & $28.3 \%$ \\
\hline
\end{tabular}




\section{Measures}

Narcissism. Level of narcissism was measured using the Narcissism Personality Inventory-16 (NPI-16) (Ames, Rose, \& Anderson, 2006). The NPI-16 consists of 16 items and was drawn from the NPI-40, made shorter and unidimensional. The NPI-16 assesses the participant's level of grandiose sense of self-worth, feelings of entitlement, need for admiration, and preoccupation with fantasies of unlimited brilliance, power, or success. The inventory requires participants to choose which item in the pair they most identify with. An example from the NPI-16 is to choose the one item most identified with from the pair: "I like having authority over people" or "I don't mind following orders." The narcissistic response is "I like having authority over people" and the non-narcissistic response is "I don't mind following orders." Another example is "I like to be the center of attention" or "I prefer to blend in with the crowd." The narcissistic response is "I like to be the center of attention" and the non-narcissistic response is "I prefer to blend in with the crowd." To determine where each respondent lands on the narcissism spectrum scale, the responses were given values. The narcissistic response was given a value of 1 and the non-narcissistic response was given a value of 2 . If the participant selected the first response, which was given a value of 1 , then he or she selected the item that reflected the narcissistic response. If the participant selected the second response, which was given a value of 2 , then he or she selected the item that reflected the non-narcissistic response. The sum of the narcissistic responses was added to determine the respondent's narcissistic score. The possible range of scores is from 0 to 16 , with higher scores representing higher levels of narcissism. The internal consistency reliability of the scale 
$(\alpha=.73)$ is considered to be acceptable as it is above the cut-off score of .70 (Taber, 2018).

Neuroticism. Level of neuroticism was measured using the Big Five Inventory (Goldberg, 1993). Neuroticism in The Big Five Inventory consists of eight items that assess the participant's level of persistent and often disproportionate worry and anxiety. There are three reverse-scored items out of the eight items. Examples from the Big Five Inventory are: "Worries a lot" and "Gets nervous easily." Examples of the reverse-scored items are: "Is relaxed, handles stress well" and "Is emotionally stable, not easily upset." The Big Five Inventory is on a 5-point Likert scale $(1=$ Strongly disagree, $2=$ Disagree, $3=$ Neither Agree nor Disagree, $4=$ Agree, 5 = Strongly Agree . The scores were then averaged to determine where each respondent landed on the neuroticism spectrum scale. The possible range of scores is from 1 to 5 , with higher scores representing higher levels of neuroticism. The internal consistency reliability of the scale $(\alpha=.80)$ is considered to be acceptable as it was above the cut-off score of .70 (Taber, 2018).

Human skills. Human skills were measured using the Skills Inventory (Northouse, 2010). The Skills Inventory consists of a 6-item scale that assess the participant's level of proficiency in working with people based on a person's knowledge about people and how they behave, operate in group, and communicate their motives, attitudes, and feelings. Example items from the Skills Inventory are: "Being able to understand others is the most important part of my work" and "I am concerned with how my decisions affect the lives of others." The Skills Inventory is on a 5-point Likert scale $(1=$ Strongly disagree, $2=$ Disagree, $3=$ Neither Agree nor Disagree, $4=$ Agree, $5=$ Strongly Agree $)$. The scores 
were then averaged to determine where each respondent landed on the spectrum for human skills. The possible range of scores is from 1 to 5 , with higher scores representing higher levels of human skills. The internal consistency reliability of the scale $(\alpha=.67)$ is right below the cut-off score of .70 (Taber, 2018).

Conceptual skills. Conceptual skills were measured using the Skills Inventory (Northouse, 2010). The Skills Inventory consists of a 6-item scale that assess the participant's level of ability to see an organization as a whole or a systematic viewpoint. Examples from the Skills Inventory are: "I would enjoy working out strategies for my organization's growth" and "Thinking about organizational values and philosophy appeals to me.” The Skills Inventory is on a 5-point Likert scale ( $1=$ Strongly disagree, 2 $=$ Disagree, $3=$ Neither Agree nor Disagree, $4=$ Agree, $5=$ Strongly Agree $)$. The scores were then averaged to determine where each respondent landed on the spectrum for conceptual skills. The possible range of scores is from 1 to 5 , with higher scores representing higher levels of conceptual skills. The internal consistency reliability of the scale $(\alpha=.69)$ is right below the cut-off score of .70 (Taber, 2018).

Demographics. Demographics were obtained with six items. These items were gender, age, education level, working status, job tenure, and work hours. The items were chosen to determine the composition of the participants and its representation of the general population. See the Appendix for the full version of questionnaires.

\section{Procedure}

In this study, the survey was administered online to participants via an online survey tool (Qualtrics). The respondents were recruited through my professional networking 
using social media sites and email. Those who viewed the social media post were provided with a brief description of the study along with the anonymous survey link and were reminded that their responses are kept anonymous and confidential.

The survey was also sent via email to professional email distribution lists that allowed solicitation of research studies. The respondents receiving the email saw a brief overview of the study and were reminded that their responses are kept anonymous and confidential. Each individual had the option to voluntarily opt in or out of the study.

Once they were directed to the survey, participants were provided with a more detailed description and the instructions. After reading the instructions, the respondents were asked to confirm their voluntary consent to participant in the study. If the respondent confirmed their consent, they were guided to the beginning of the of the survey items. If the respondent chose the option not to participate, they were led to the end of the survey and were thanked for their interest.

The respondents who gave consent to participate in the survey first responded to the demographic items. Next, the participants responded to the items that measured narcissism, neuroticism, and leadership skills (human skills and conceptual skills). Once all surveys were finished, the data were statistically analyzed using Statistical Package for Social Sciences (SPSS) version 25. 


\section{Results}

\section{Descriptive Statistics}

Descriptive statistics were calculated to determine the central tendency and variability of the measured variables and can be seen in Table 2. Narcissism had a mean below the midpoint of $7(M=4.81)$ with relatively small variability $(S D=$ 3.14). This means that the sample perceived themselves slightly low on the narcissism spectrum scale, with low levels of a grandiose sense of self-worth, feelings of entitlement, need for admiration, and preoccupation with fantasies of

unlimited brilliance, power, or success. Neuroticism had a mean approximately at the midpoint $(M=2.99)$ with relatively small variability $(S D=.65)$. This means that the sample perceived themselves relatively consistent to respond with negative emotions to threat, frustration, and loss.

The human skills dimension of leadership skills had a mean relatively higher than the midpoint $(M=3.81)$ with relatively small variability $(S D=.54)$. This means that the sample perceived themselves stronger in the ability to work cooperatively with others, inspire enthusiasm, motivate and build trust. The conceptual skills dimension of leadership skills had a mean slightly higher than the midpoint $(M=3.76)$ with relatively small variability $(S D=.57)$. This means that the sample perceived themselves stronger in the ability to see an organization as a whole or to have a systematic viewpoint. 
Table 2

Descriptive Statistics of Variables $(N=145)$

\begin{tabular}{lrrc}
\hline \multicolumn{1}{c}{ Variable } & $M$ & \multicolumn{1}{c}{$S D$} & Range \\
\hline Narcissism & 4.81 & 3.14 & $0-14$ \\
Neuroticism & 2.99 & .65 & $1-5$ \\
Leadership Skills & & & \\
$\quad$ Human Skills & 3.81 & .54 & $1-5$ \\
$\quad$ Conceptual Skills & 3.76 & .57 & $1-5$ \\
\hline
\end{tabular}

\section{Tests of Research Hypotheses}

Table 3 presents the Pearson correlations for narcissism, neuroticism, human skills, and conceptual skills. Hypothesis 1a predicted that narcissism would be negatively related to human skills. Pearson correlation analysis were performed to examine the relationship between narcissism and human skills. Results showed that there was no significant relationship between narcissism and human skills ( $r$ $=-.01, p>.05)$. Thus, Hypothesis 1a was not supported.

Hypothesis $1 \mathrm{~b}$ predicted that narcissism would be negatively related to conceptual skills. Pearson correlation analysis were performed to examine the relationship between narcissism and conceptual skills. Results showed that there was no significant relationship between narcissism and conceptual skills $(r=.12$, $p>.05)$. Thus, Hypothesis $1 \mathrm{~b}$ was not supported. 
Table 3

Pearson Correlations, Predictor and Criterion Variables $(N=145)$

\begin{tabular}{lllll}
\hline \multicolumn{1}{c}{ Variable } & 1 & 2 & 3 & 4 \\
\hline 1. Narcissism & -- & & & \\
2. Neuroticism & $-.22 * *$ & -- & & \\
3. Leadership - Human Skills & -.01 & $-.24 * *$ & -- & - \\
4. Leadership - Conceptual Skills & .12 & $-.30 * * *$ & $.52 * * *$ & - \\
\hline Note. $* \mathrm{p}<.05, * * \mathrm{p}<.01, * * * \mathrm{p}<.001$ & & & &
\end{tabular}

Hypothesis 2a predicted that neuroticism would be negatively related to human skills. Pearson correlation analysis was performed to examine the relationship between neuroticism and human skills. Results showed that neuroticism had a significant, moderate negative relationship with human skills ( $r$ $=-.25, p<.01)$. The more neurotic individuals were, the fewer human skills they had. Thus, Hypothesis 2a was supported.

Hypothesis $2 \mathrm{~b}$ predicted that neuroticism would be negatively related to conceptual skills. Pearson correlation analysis was performed to examine the relationship between neuroticism and conceptual skills. Results showed that neuroticism had a significant, moderate negative relationship with conceptual skills $(r=-.30, p<.001)$. The more neurotic individuals were, the fewer conceptual skills they had. Thus, Hypothesis $2 \mathrm{~b}$ was supported.

To summarize the results of the research hypotheses, narcissism and neuroticism differed in their relationship with the leadership skills dimensions. 
Narcissism did not have a significant relationship with the two dimensions of leadership skills (human skills and conceptual skills). Neuroticism was moderately related to the two dimensions of leadership skills. Hypothesis 1a and $1 \mathrm{~b}$ were not supported, while Hypothesis $2 \mathrm{a}$ and $2 \mathrm{~b}$ were supported.

\section{Pearson Correlations by Age}

Pearson correlations were conducted by age groups to see whether the relationships between neuroticism and the two dimensions of leadership skills varied as a function of characteristics of participants. More specifically, the study explored whether the relationships between neuroticism and the two dimensions of leadership skills varied as a function of the age of the participants. In order to explore this question, subsamples needed to be created. A median split of age was conducted and then came up with two subsamples: those respondents younger than 25 years old $(n=76)$ and those respondents 25 years or older $(n=69)$. Next, Pearson correlations were conducted between neuroticism and the two dimensions of leadership skills for the two subsamples.

Pearson correlation analyses were performed to examine the relationship between neuroticism and the two types of leadership skills (human skills and conceptual skills) for employees younger than 25 years old (see Table 4). For these employees, neuroticism was not significantly related to human skills $(r$ $=.03, p>.05)$ or conceptual skills $(r=.00, p>.05)$.

Pearson correlation analyses were performed to examine the relationship between neuroticism and the two types of leadership skills (human skills and conceptual skills) for employees 25 years or older (see Table 5). For these 
employees, neuroticism had a strong negative relationship with human skills $(r=-$

$.38, p<.01)$ and conceptual skills $(r=-.44, p<.001)$.

Table 4

Pearson Correlations, Neuroticism and Criterion Variables - Age $<25$ years $(N=76)$

\begin{tabular}{llll}
\hline \multicolumn{1}{c}{ Variable } & 1 & 2 & 3 \\
\hline 1. Neuroticism & -- & & \\
2. Leadership - Human Skills & .03 & -- & \\
3. Leadership - Conceptual Skills & .00 & $.56 * * *$ & -- \\
\hline Note. ${ }^{*} \mathrm{p}<.05, * * \mathrm{p}<.01, * * * \mathrm{p}<.001$ & & &
\end{tabular}

Pearson correlation analyses were performed to examine the relationship between neuroticism and the two types of leadership skills (human skills and conceptual skills) for employees 25 years or older (see Table 5). For these employees, neuroticism had a strong negative relationship with human skills ( $r=-$ $.38, p<.01)$ and conceptual skills $(r=-.44, p<.001)$.

These results suggested that the relationship between neuroticism and leadership skills (human skills and conceptual skills) depended on age. Neuroticism among employees younger than 25 years old did not have a significant relationship with leadership skills, but those employees 25 years or older had a strong negative relationship with leadership skills. These results suggested that the more neurotic employees who were 25 years or older, the fewer human and conceptual skills they had. 
Table 5

Pearson Correlations, Neuroticism and Criterion Variables - Age $\geq 25$ years $(N=69)$

\begin{tabular}{llll}
\hline \multicolumn{1}{c}{ Variable } & 1 & 2 & 3 \\
\hline 1. Neuroticism & -- & \\
2. Leadership - Human Skills & $-.38 * *$ & -- & \\
3. Leadership - Conceptual Skills & $-.44 * * *$ & $.46 * * *$ & -- \\
\hline Note. $* \mathrm{p}<.05, * * \mathrm{p}<.01, * * * \mathrm{p}<.001$ & &
\end{tabular}




\section{Discussion}

Simply having the responsibilities of a leader does not necessarily make a person an effective leader. There are many leadership skills and competencies that, when combined and applied, make an effective leader. More specifically, this study aimed to look at the following two dimensions of leadership skills: human skills and conceptual skills.

Previous research has found a negative relationship between narcissism and human skills, and an inconsistent relationship between narcissism and conceptual skills. Previous research has also found a negative relationship between neuroticism and human skills, although the relationship between neuroticism and conceptual skills has not been tested. The present study identified a few gaps: the inconsistent relationship between narcissism and conceptual skills, and the unexamined relationship between neuroticism and conceptual skills. The present study also elaborated on the little research on the relationship between narcissism and human skills, and neuroticism and human skills. The purpose of the present study was to clarify the relationship between narcissism and neuroticism and leadership skills (human skills and conceptual skills).

\section{Summary of Findings}

Hypothesis 1a stated that narcissism is negatively related to human skills and Hypothesis $1 \mathrm{~b}$ stated that narcissism is negatively related to conceptual skills. These hypotheses were not supported. Narcissism did not show a negative relationship with human skills nor with conceptual skills. The findings regarding the relationship between narcissism and human skills are inconsistent with previous findings. For example, Cheek and colleagues (2018) found that narcissism had a significant, positive relationship with 
interpersonal impairment. The present study found no significant relationship between narcissism and human skills. The findings regarding the relationship between narcissism and conceptual skills are consistent with previous findings. Research on the relationship between narcissism and conceptual skills is limited and the relationship appears to be uncertain (Blair et al., 2008).

Hypothesis 2a stated that neuroticism is negatively related to human skills and Hypothesis $2 \mathrm{~b}$ stated that neuroticism is negatively related to conceptual skills. These hypotheses were supported. Neuroticism was negatively related to both human skills and conceptual skills. The results indicate that the more neurotic employees are, the fewer human skills they have. The results also indicate that the more neurotic employees are, the fewer conceptual skills they have. The findings regarding the relationship between neuroticism and human skills are consistent with previous findings. For example, Feitosa (2013) found neuroticism had a significant, negative relationship with social skills. Previous research has not looked at the relationship between neuroticism and conceptual skills, therefore this study is the first to look at the relationship.

In addition to the hypotheses predicted, the present study also examined the relationship between neuroticism and leadership skills based on age. The relationship between neuroticism and leadership skills differed based on the age of participants (younger than 25 years old vs. 25 years or older). There was no relationship between neuroticism and both human skills and conceptual skills for employees younger than 25 years. Neuroticism had a significant, negative relationship with human and conceptual skills for employees 25 years or older. These results suggest that the relationship between 
neuroticism and leadership skills depends on age. The more neurotic employees who are 25 years or older, the fewer human and conceptual skills they have.

\section{Theoretical Implications}

There are a number of theoretical implications of the present study. First, this study filled several literature gaps in the leadership skills literature. There is limited previous research on the relationships between narcissism, neuroticism, and leadership skills (human skills and conceptual skills), which this study expanded on. This study was the first to introduce the negative relationship between neuroticism and conceptual skills. As for the relationship between neuroticism and human skills, the present study supported previous literature on the negative relationship.

Second, this study also examined the relationship between narcissism and leadership skills. The present study found no significant relationship between narcissism and human skills, whereas previous research (Feitosa, 2013) found a negative relationship. The relationship between narcissism and conceptual skills are still uncertain, as previous literature and this study have found no significant relationship.

Finally, this study examined the relationship between neuroticism and leadership skills based on subsamples of age (younger than 25 years vs. 25 years or older). The relationship between neuroticism and leadership skills differed based on age. Neuroticism for employees 25 years or older was negatively related to both human skills and conceptual skills. This means that employees 25 years or older had fewer leadership skills the more neurotic they were. As for neuroticism in employees younger than 25 , there was no significant relationship. Results indicated that the older a neurotic employee is, the 
fewer leadership skills they have. It is plausible that other demographic variables might interact with the relationship between neuroticism and leadership skills.

\section{Practical Implications}

One practical implication of the present study is that neuroticism could be used to improve the interview process for leadership positions. During the hiring process, it is common to ask personality-related questions to test candidates' fit for the job position. If neuroticism questions are included in the hiring process for leadership positions, then hiring managers can eliminate those candidates scoring high on neuroticism from the candidate pool. Candidates scoring high on neuroticism should be considered for removal from the candidate pool because they have fewer leadership skills, more specifically, human skills and conceptual skills.

Another practical implication of the present study is that age of candidates could be used to improve interpretation of personality test results. As seen in this study, the relationship between neuroticism and leadership skills depended on the employee's age. After creating subsamples, only employees 25 years or older had a clear negative relationship with leadership skills. Those employees 25 years or older who score high on neuroticism should be considered for removal from the hiring process. Neuroticism among employees younger than 25 years old did not have a significant relationship with leadership skills, therefore, those neurotic candidates younger than 25 years old would not need to be eliminated from the candidate pool.

Finally, the findings that narcissism had no relationship with leadership skills indicate that narcissism should not be looked at when assessing employees' leadership skills. It 
has been found that many of narcissists" characteristics are "leader-like" (Ensari et al., 2011; Judge et al., 2002), therefore, it makes sense to research the relationship between narcissism and leadership skills. Although previous research says that many narcissists' characteristics are "leader-like", the present study indicates that it does not mean narcissists have leadership skills, rather there was no relationship. Therefore, narcissism should not be included in personality questionnaires when hiring for leadership positions.

\section{Strengths of the Study}

The present study addressed the gaps regarding the unclear relationships between neuroticism and human skills, and neuroticism and conceptual skills. There was limited research on the relationship between neuroticism and human skills, although a majority of the research found a negative relationship, which is supported in this study. There was no research on the relationship between neuroticism and conceptual skills, therefore, this study was the first to look at this relationship. By doing so, this study increased the understanding of the relationship between neuroticism and leadership skills (human skills and conceptual skills). It also provides evidence that the relationship between neuroticism and leadership skills depends on age (younger than 25 vs. 25 or older).

\section{Limitations and Future Research}

Consistent with many studies, the present study is not without limitations. Starting with the demographic and background characteristics, employee's tenure was not diverse. The majority of the participants had a relatively short tenure: 51 participants $(35.2 \%)$ were at their current job for less than one year, and 65 participants $(44.8 \%)$ were at their current job for 1 to 3 years. Only $19.3 \%$ of participants had a tenure ranging from 4 - 
more than 10 years. Tenure may have an impact on leadership skills due to years of work experience. It would be interesting to see a larger sample of employees with longer tenure and their results on the relationships between narcissism, neuroticism, and leadership skills. Thus, a future study should have a more diverse sample in regard to tenure.

Another limitation of the present study is the use of self-report for the questionnaires on narcissism, neuroticism, and leadership skills. Self-report studies have many advantages, but they also suffer from specific disadvantages due to the way that participants generally behave. Participants may exaggerate or lie in order to get desirable results. There are also cases when respondents guess the hypothesis of the study and provide biased responses that: confirm the researcher's hypotheses, make them look good, or, make them appear more distressed. Future research should consider changing the survey methodology, possibly to observation of employees, which may provide more accurate results.

Lastly, the questionnaire for leadership skills is a limitation to the present study. The Skills Inventory was the questionnaire used to measure leadership skills (human skills and conceptual skills), which is not a widely used questionnaire. Future research should consider a few things regarding the leadership skills questionnaire. First, this study included two of the three dimensions of The Skills Inventory. Technical skills were not looked at because it looks at the competencies in a specialized area (e.g. Human Resource Manager) and I did not have access to a large specialized sample to accomplish this. Future research should look at all three dimensions of The Skills Inventory (Human, Conceptual and Technical skills). Secondly, future research should look into other 
leadership skills questionnaires that are more credible and widely used. The Skills Inventory may not accurately measure leadership skills, therefore other questionnaires should be tested.

\section{Conclusion}

The goal of this study was to examine the relationship between narcissism, neuroticism, and leadership skills (human skills and conceptual skills). This study found there to be a negative relationship between neuroticism and human skills. These results suggest that the more neurotic people are, the fewer human skills they have. This study also found there to be a negative relationship between neuroticism and conceptual skills. These results suggest that the more neurotic people are, the fewer conceptual skills they have. Although this study suggested a strong negative relationship between neuroticism and the two dimensions of leadership skills, the results varied when age was accounted for. Neuroticism for employees younger than 25 years old was not significantly related to the two dimensions of leadership skills. Neuroticism for employees 25 years or older was strongly related to the two dimensions of leadership skills. This study found there to be no significant relationship between narcissism and leadership skills (human skills and conceptual skills). 


\section{References}

Adams, S. (2013). Leadership tip: Hire the quiet neurotic, not the impressive extrovert. Forbes. Retrieved at:

https://www.forbes.com/sites/susanadams/2013/04/11/leadership-tip-hire-the-quietneurotic-not-the-impressive-extrovert/\#52d0e3c4788b.

Ames D. R., Rose, P., \& Anderson, P. (2006). The NPI-16 as a short measure of narcissism. Journal of Research in Personality, 40, 440-450.

doi:10.1016/j.jrp.2005.03.002.

Anderson, N. E., \& Kiehl, K. A. (2014). Psychopathy: Developmental perspectives and their implications for treatment. Restorative Neurology and Neuroscience, 32, 103 117. doi:10.3233/RNN-139001.

Ashton, M. C., \& Lee, A. K. (2007). Empirical, theoretical, and practical advantages of the HEXACO model of personality structure. Personality and Social Psychology Review, 11, 150-166. doi:10.1177/1088868306294907.

Back, M. D., Schmukle, S. C., \& Egloff, B. (2010). Why are narcissists so charming at first sight? Decoding the narcissism-popularity link at zero acquaintance. Journal of Personality and Social Psychology, 98, 132-145.

Bagchi, A., \& Bandyopadhyay, S. (2016). Workplace deviance and recession. The B.E. Journal of Theoretical Economics, 16, 47-81.

Blair, C. A., Hoffman, B. J., \& Helland, K. R. (2008). Narcissism in organizations: A multisource appraisal reflects different perspectives. Human Performance, 21, 254276. doi:10.1080/08959280802137705.

Borman, W. C., \& Motowidlo, S. J. (2000). Contextual performance and organizational citizenship behavior in human resource management. Human Resource Management Review, 10, 1-2. doi:10.1016/S1053-4822(99)00035-2.

Bressert, S. (2019). Narcissistic Personality Disorder. Psych Central. Retrieved at: https://psychcentral.com/disorders/narcissistic-personality-disorder/.

Brief, A., \& Motowidlo, S. (1986). Prosocial organizational behaviors. The Academy of Management Review, 11, 710-725. doi:10.2307/258391.

Brunell, A. B., Gentry, W. A., Capmbell, W. K., Hoffman, B. J., Kuhnert, K. W., \& Demarree, K. G. (2008). Leader emergence: The case of the narcissistic leader. Personality and Social Psychology Bulletin, 34, 1663-1676.

doi:10.1177/0146167208324101. 
Carmeli, A., \& Tishler, A. (2006). The relative importance of the top management team's managerial skills. International Journal of Manpower, 27, 9-36.

Cheek, J., Kealy, D., Joyce, A. S., \& Ogrodniczuk, J. S. (2018). Interpersonal problems associated with narcissism among psychiatric outpatients: A replication study. Archives of Psychiatry and Psychotherapy, 2, 26-33. doi:10.12740/APP/90328.

Costa, P. T., \& McCrae, R. R. (1980). Influence of extraversion and neuroticism on subjective well-being: Happy and unhappy people. Journal of Personality and Social Psychology, 38, 668-678.

El-Sabaa. S. (2001). The skills and career path of an effective project manager. International Journal of Project Management, 19, 1-7.

Ensari, N., Riggio, R. E., Christian, J., \& Carslaw, G. (2011). Who emerges as a leader? Meta-analyses of individual differences as predictors of leadership emergence. Personality and Individual Differences, 51, 532-536.

Feitosa, F. B. (2013). Social skills and psychological suffering. Arquivos Brasileiros de Psichologia, 65, 38-50.

Grijalva, E., Harms, P. D., Newman, D. A., Gaddis, B. H., \& Fraley, R. C. (2015). Narcissism and leadership: A meta-analytic review of linear and nonlinear relationships. Personnel Psychology, 68, 1-47. doi:10.1111/peps.12072.

Goldberg, L. R. (1993). The structure of phenotypic personality traits. American Psychologist, 48, 26-34.

Javadin, S. R., Tehrani, F. A., \& Ramezani, A. (2010). Studying the relationship between managerial skills and efficiency of bank branches. World Applied Sciences Journal, $11,170-177$.

Jenkins-Guarnieri, M. A., Wright, S. L., \& Johnson, B. D. (2013). The interrelationships among attached style, personality traits, interpersonal competency, and Facebook use. Psychology of Popular Media Culture, 2, 117-131. doi:10.1037/a0030946.

Jex, S. M. (2002). Organizational Psychology: A Scientist-Practitioner Approach. New York, NY: John Wiley \& Sons, Inc.

Judge, T. A., Heller, D., \& Mount, M. K. (2002). Five-factor model of personality and job satisfaction: A meta-analysis. Journal of Applied Psychology, 87, 530-541. 
Judge, T. A., LePine, J. A., \& Rich, B. L. (2006). Loving yourself abundantly: Relationship of the narcissistic personality to self- and other perceptions of workplace deviance, leadership, and task and contextual performance. Journal of Applied Psychology, 91, 762-776.

Kaifi, B. A., \& Mujtaba, B. G. (2010). A study of management skills with Indian respondents: Comparing their technical, human and conceptual scores based on gender. Journal of Applied Business and Economics, 11, 1-10.

Kanten, P. (2014). The moderating role of organizational climate in the effect of narcissistic personality characteristic on organizational citizenship behavior. Journal of Management, 25, 160-184.

Katz, D., \& Kahn, R. L. (1966). The Social Psychology of Organizations. New York, NY: John Wiley \& Sons, Inc.

Katz, R. L. (1955). Skills of an Effective Administrator. Harvard Business Review, 33, 33-42.

Katz, R. L. (1974). Skills of an Effective Administrator. Harvard Business Review, 5, 90102.

Kets de Vries, M. F., \& Miller, D. (1985). Narcissism and leadership: An object relations perspective. Human Relations, 38, 583-601. doi:10.1177/001872678503800606.

Lahey, B. B. (2009). Public health significant of neuroticism. American Psychologist, 64, 241-256. doi:10.1037/a0015309.

Mahajan, T., \& Chaturvedi, S. (2013). Impact study of blended learning on functional effectiveness factor of managerial effectiveness. Journal of Management Research, $13,209-218$.

McFarlin, D., \& Sweeney, P. D. (2010). International Management: Strategic Opportunities \& Cultural Challenges (4th ed.). Abingdon, UK: Routledge.

Men, L. R., \& Yue, C. A. (2019). Creating a positive emotional culture: Effect on internal communication and impact on employee supportive behaviors. Public Relations Review, 45, 1-12.

Mumford, M. D., Marks, M. A., Connelly, M. S., Zaccaro, S. J., \& Reiter-Palmon, R. (2000). Development of leadership skills: Experience and timing. Leadership Quarterly, 11, 87-114. 
Muthuveloo, R., Chiek, K. C., \& Ping, T. A. (2017). An empirical analysis of the perceived skills in predicting managerial effectiveness: The Malaysian perspective. Global Business and Management Research: An International Journal, 9, 41-59.

Nevicka, B., De Hoogh, A. H. B., Van Vianen, A. E. M., Beersma, B., \& Mcllwain, D. (2011a). All I need is a stage to shine: Narcissists' leader emergence and performance. The Leadership Quarterly, 22, 910-925.

Nevicka, B., Ten Velden, F. S., De Hoogh, A. H. B., \& Van Vianen, A. E. M. (2011b). Reality at odds with perceptions: Narcissistic leaders and group performance. Psychological Science, 22, 1259-1264. doi:10.1177/0956797611417259.

Northouse, P. G. (2007). Leadership: Theory and Practice (4th ed.). Thousand Oaks, CA: Sage Publications, Inc.

Northouse, P. G. (2010). Skills Inventory - Leadership: Theory and Practice (5th ed.). Thousand Oaks, CA: Sage Publications, Inc.

Northouse, P. G. (2012). Leadership: Theory and Practice (6th ed.). Thousand Oaks, CA: Sage Publications, Inc.

Ones, D. S., Viswesvaran, C., \& Dilchert, S. (2005). Personality at work: Raising awareness and correcting misconceptions. Human Performance, 18, 389-494.

Ozer, D. J., \& Benet-Martinez, V. (2006). Personality and the prediction of consequential outcomes. Annual Review of Psychology, 57, 401-421. doi:10.1146annurev.psych.57.102904.190127.

Paulhus, D. L. (1998). Interpersonal and intrapsychic adaptiveness of trait selfenhancement: A mixed blessing? Journal of Personality and Social Psychology, 74, 1197-1208.

Rihal, C. S. (2017). The importance of leadership to organizational success. NEJM Catalyst. Retrieved at: https://catalyst.nejm.org/importance-leadership-skillsorganizational-success/.

Rubin, R. S., Bommer, W. H., \& Baldwin, T. T. (2002). Using extracurricular activity as an indicator of interpersonal skill: prudent evaluation or recruiting malpractice? Human Resource Management, 41, 441-454. doi:10.1002/hrm.10053.

Salovey, P., \& Pizarro, D. A. (2003). The value of emotional intelligence. In R. J. Sternberg, J. Lautrey, \& T. I. Lubart (Eds.), Models of intelligence: International perspectives (p. 263-278). American Psychological Association. 
Sanyal, R. N., \& Guvenli T. (2004). Perception of managerial characteristics and organizational performance: Comparative evidence from Israel, Slovenia, and the USA. Cross Cultural Management: An International Journal, 11, 35-57.

Schnake, M. (1991). Organizational citizenship: A review, proposed model, and research agenda. Human Relations, 44, 735-759.

Spector, P. (1997). Job Satisfaction: Application, Assessment, Causes and Consequences. Thousand Oaks, CA. Sage Publications, Inc.

Taber, K.S. (2018). The use of cronbach's alpha when developing and reporting research instruments in science education. Research in Science Education, 48, 1273-1296.

Tamas, I., Andras, L., \& Tamas, B. (2016). A darker shade of love: Machiavellianism and positive assortative mating based on romantic ideals. European Journal of Psychology, 12, 137-152. doi:10.5964.ejop.v12i1.1007.

Teoh, A. P., Lee, K. Y., \& Muthuveloo, R. (2017). The impact of enterprise risk management, strategic agility, and quality of internal audit function on firm performance. Econjournals, 7, 222-229.

Tonidandel, S., Braddy, P., \& Fleenor, J. (2012). Relative importance of managerial skills for predicting effectiveness. Journal of Managerial Psychology, 27, 636-655. doi:10.1108/02683941211252464.

Tuteja, N., \& Sharma, P. K. (2017). Linking job performance and big five personality traits of employees in Chandigarh IT sector. Scholarly Research Journal for Humanity Science \& English Language, 6, 7358-7370.

Vlasveld, M. C., van der Feltz-Cornelis, C., Anema, J. R., van Mechelen, W., Beekman, A. T. F., van Marwijk, H. W. J., \& Penninx, B. W. J. H. (2013). The associations between personality characteristics and absenteeism: A cross-sectional study in workers with and without depressive and anxiety disorders. Journal of Occupational Rehabilitation, 23, 309-317.

Yukl, G. (2002). Leadership in Organizations (5th ed.). Upper Saddle River, NJ: Prentice Hall.

Yukl, G. (2006). Leadership in Organizations (6th ed.). Upper Saddle River, NJ: Prentice Hall. 


\section{Appendix}

\section{Demographic Items}

What is your age?

What is your gender?

What is the highest level of education you've last completed?

What is your current employment status?

How long have you worked in your current position?

On average, how many hours do you work per week?

\section{Scale Items}

\section{Narcissism}

I know that I am good because everybody keeps telling me so.

When people compliment me, I sometimes get embarrassed.

I like to be the center of attention.

I prefer to blend in with the crowd.

I think I am a special person.

I am not better or worse than most people.

I like having authority over other people.

I don't mind following orders.

I find it easy to manipulate people.

I don't like it when I find myself manipulating people.

I insist upon getting the respect that is due me.

I usually get the respect that I deserve.

I am apt to show off if I get the chance.

I try not to be a show off. 
I always know what I am doing.

Sometimes I am not sure of what I am doing.

Everybody likes to hear my stories.

Sometimes I tell good stories.

I expect a great deal from other people.

I like to do things for other people.

I really like to be the center of attention.

It makes me uncomfortable to be the center of attention.

People always seem to recognize my authority.

Being an authority doesn't mean that much to me.

I am going to be a great person.

I hope I am going to be successful.

I can make anybody believe anything I want them to.

People sometimes believe what I tell them.

I am more capable than other people.

There is a lot that I can learn from other people.

I am an extraordinary person.

I am much like everybody else.

\section{Neuroticism}

Is depressed, blue.

Is relaxed, handles stress well. *

Can be tense.

Worries a lot.

Is emotionally stable, not easily upset. *

Can be moody.

Remains calm in tense situations. *

Gets nervous easily. 


\section{Leadership Skills: Human Skills Items}

Being able to understand others is the most important part of my work.

My main concern at work is to have a supportive communication climate.

Understanding the social fabric of the organization is important to me.

Getting all parties to work together is a challenge I enjoy.

I am concerned about how my decisions affect the lives of others.

As a rule, adapting my ideas to other people's needs is easy for me.

\section{Leadership Skills: Conceptual Skills Items}

Seeing the big picture comes easy for me.

I am intrigued by complex organizational problems.

I enjoy working out strategies for my organization's growth.

Creating a mission statement is rewarding work.

Thinking about organizational values and philosophy appeals to me.

I enjoy working with abstract ideas.

*Indicates that survey items were reverse-coded. 